\title{
ESTIMATIVA DO VOLUME MÁXIMO DE CALDA PARA APLICAÇÃO FOLIAR DE PRODUTOS QUÍMICOS NA CULTURA DE MILHO ${ }^{1}$
}

\author{
Maria del Valle Basanta ${ }^{2,4}$; Durval Dourado-Neto ${ }^{3,5 *}$; Axel García y García ${ }^{2,5}$ \\ ${ }_{3}^{2}$ Pós-Graduandos do Depto. de Produção Vegetal - USP/ESALQ. \\ ${ }^{3}$ Depto. de Produção Vegetal - USP/ESALQ, C.P. 9 - CEP: 13418-900 - Piracicaba, SP. \\ ${ }_{5}^{4}$ Bolsista FAPESP. \\ ${ }^{5}$ Bolsista CNPq. \\ *Autor correspondente <dourado@carpa.ciagri.usp.br>
}

RESUMO: Com o objetivo de estimar o volume de água por hectare retido na folhagem da cultura de milho para fins de quimigação (alvo folha), é proposto um modelo, tendo sido conduzido um experimento em que foi avaliada a interceptação de água pela parte aérea das plantas de milho sob diferentes lâminas de irrigação aplicadas via pivô central. Foi semeado um híbrido de milho, em três densidades, obtendo-se assim três arranjos espaciais diferentes. As avaliações foram realizadas em 3 estádios fenológicos: i) 4-5 folhas; ii) 8 folhas e iii) 14 folhas. A quantidade de água retida nas folhas das plantas foi estimada subtraindo à massa total da planta medida após a passagem do pivô, a massa de matéria seca e a água constitutiva das plantas. Para a análise estatística dos resultados, utilizou-se um delineamento experimental em parcelas subdivididas no tempo, com quatro repetições. O tratamento principal foi a população de plantas e o subtratamento a data de amostragem. A área foliar foi avaliada em cada amostragem. A fenologia e o desenvolvimento relativo da cultura foram avaliados periodicamente. Os resultados permitiram verificar que o modelo proposto é utilizável. Palavras-chave: Zea mays, quimigação, irrigação, modelagem

\section{ESTIMATION OF THE MAXIMUM WATER VOLUME FOR CHEMICAL PRODUCT APPLICATION ON CORN LEAVES}

\begin{abstract}
With the objective of estimating the volume of water retained by corn leaves per unit area (ha) for chemigation purposes, a simple model is proposed. A field experiment was carried out to obtain the water interception on the aerial corn plant parts under a center pivot irrigation system. Three plant populations were used to obtain different designs, the measurements having been performed at three phenological stages: i) 45 leaves; ii) 8 leaves and iii) 14 leaves. The water mass retained by the corn leaves was obtained considering the total plant mass (measured after irrigation), the plant dry weight and the plant constitution water mass. Treatments were arranged in a split-plot design, with four replications. Main plot treatment was plant population and subplot treatment was sampling date. Total plant leaf area was evaluated for each sampling period. Phenology and the relative crop development were evaluated periodically. Results indicate that the proposed model can be used for this estimate.
\end{abstract}

Key words: Zea mays, chemigation, irrigation, crop modeling

\section{INTRODUÇÃO}

Em todos os sistemas de produção é necessário otimizar o uso dos recursos produtivos. Isso se obtém por meio de altas produtividades e da redução dos custos de produção. Para as culturas em geral, o uso da técnica de irrigação e a aplicação de agroquímicos são fundamentais se o objetivo é a obtenção de altos rendimentos. A técnica de quimigação, aplicação de produtos químicos via água de irrigação, é uma combinação dessas duas técnicas.

Com a quimigação é possível uma aplicação segura e efetiva da quantidade apropriada de produto, pela qual reduz-se os custos de produção enquanto se protege 0 operário e o ambiente (Leon New, 1990). O sucesso da quimigação, tendo como alvo tanto o solo quanto a folhagem, depende em grande parte da uniformidade de aplicação do produto, a qual é geralmente proporcional à uniformidade de distribuição da água pelo sistema de irrigação. A medição da uniformidade de distribuição da água mediante o coeficiente de uniformidade (Christiansen, 1942) permite a comparação dos diferentes sistemas de irrigação em relação a esse parâmetro. Porém, esse coeficiente mostra a forma em que é distribuída a água no solo pelo sistema de irrigação sem a presença da cultura.

O controle químico de pragas via injeção de inseticidas na água de irrigação (insetigação) começou na década de 60 nos Estados Unidos. No Brasil os primeiros relatos datam da década de 80 . Com o incremento da área agrícola irrigada, os inseticidas têm sido aplicados por meio dos equipamentos de aspersão sem as pesquisas prévias necessárias para a sua eficiente utilização (Viana, 1994). 
Sendo possível a aplicação dessa técnica com todos os métodos de irrigação, eles apresentam alguns usos mais apropriados e, em muitos casos impõem restrições ao tipo de produto químico a ser aplicado. Particularmente, na irrigação por aspersão pode-se aplicar os produtos químicos tanto no solo quanto nas folhas das plantas, enquanto que os sistemas de irrigação por superfície e por gotejamento só permitem aplicar o agroquímico ao solo. A maioria dos inseticidas, fungicidas e agentes de controle biológico, bem como herbicidas pósemergentes, precisa ser aplicado na parte aérea das plantas (Vieira, 1994).

Em presença de cultura, a água aplicada pelo sistema de irrigação será redistribuída entre a parte aérea das plantas e o solo. Essa distribuição dependerá de fatores do sistema de irrigação (caracterizados pelo coeficiente de uniformidade e a lâmina aplicada, principalmente), do clima (velocidade do vento e evaporação) e da cultura (espécie, densidade de semeadura e arquitetura de planta, disposição das folhas na planta e ângulo de inserção, e estádio fenológico). Essas observações mostram a importância da cultura na distribuição da água de irrigação e da potencialidade da aplicação de agroquímicos na folhagem das culturas por meio dos sistemas de irrigação.

A maior parte dos trabalhos sobre interceptação foliar foram feitos em ecossistemas florestais ou em culturas perenes de grande porte (Linsley et al., 1949; Lima, 1976; Leopoldo, 1981; Miranda \& Butler, 1986; Rao, 1987), porém em culturas anuais não é muito freqüente encontrar trabalhos sobre o tema. Em culturas anuais a interceptação aumenta com a idade da cultura devido ao acréscimo da cobertura do solo pelas folhas, com posterior queda no período de maturação. O contrário acontece com a quantidade de água que não é interceptada pela parte aérea (folha e colmo) da planta e chega ao solo ("precipitação interna"), que é inversamente proporcional à idade da cultura (Leopoldo et al., 1981).

Mundim (1996) estudou o efeito da cultura de milho na distribuição da água aplicada por aspersão convencional. Encontrou valores de escoamento pelo colmo de 45 a $50 \%$ da água que atingiu o solo irrigado com lâminas de 3 e 4 mm, e que a "precipitação interna" é intensificada com o aumento da lâmina aplicada.

O presente trabalho foi realizado com no intuito de fornecer subsídio para definir a viabilidade da técnica de quimigação cujo alvo é folha. Sendo assim, foi proposto um modelo com o objetivo de determinar o volume máximo de água, por unidade de área, retido na folhagem da cultura de milho.

\section{MATERIAL E MÉTODOS}

O experimento foi conduzido em Piracicaba-SP $\left(22^{\circ} 43^{\prime}\right.$ latitude Sul, $47^{\circ} 38^{\prime}$ longitude Oeste, $580 \mathrm{~m}$ de altitude) na área experimental do Departamento de Produção Vegetal da USP/ESALQ. O solo da área é classificado como Terra Roxa Estruturada eutrófico, horizonte A moderado, textura argilosa/muito argilosa.

Foram instaladas 24 parcelas dispostas em grupos de 12, correspondendo cada um deles a uma determinada lâmina de irrigação (a irrigação foi feita utilizando o sistema de irrigação do tipo pivô central). A área total de cada parcela foi de $37,5 \mathrm{~m}^{2}$ ( $6 \mathrm{~m}$ de cumprimento e 7 fileiras de plantas com espaçamento de $0,85 \mathrm{~m}$ ) e a área útil de $17 \mathrm{~m}^{2}$. Os tratamentos foram aleatoriamente distribuídos dentro de cada grupo de 12 parcelas e as lâminas de irrigação foram determinadas aleatoriamente entre os dois grupos de parcelas. Para cada grupo de 12 parcelas foi utilizado um delineamento em parcelas subdivididas, sendo o tratamento principal a população de plantas e o subtratamento a época de avaliação.

$\mathrm{Na}$ área experimental do pivô central do Departamento de Produção Vegetal da ESALQ foi semeado o híbrido de milho CARGILL 909 (super-precoce) em 28 de agosto de 1998 com três densidades: i) 3,5 sementes/m linear e um espaçamento entre fileiras de 0,85 m (41.000 planta ha $\left.{ }^{-1}\right)$, ii) 4,5 sementes/m linear e um espaçamento entre fileiras de $0,85 \mathrm{~m}$ (53.000 planta ha ${ }^{1}$ ), iii) 5,5 sementes/m linear e um espaçamento entre fileiras de $0,85 \mathrm{~m}$ (65.000 planta ha $\left.{ }^{-1}\right)$. As sementes foram tratadas com o fungicida thiabendazolle na dose de $300 \mathrm{~g} /$ $100 \mathrm{~kg}$. Para o controle de pragas utilizou-se lambda cyalotrin para a lagarta rosca e lufenuron e clorpyrifos para a lagarta do cartucho. Para o controle da plantas daninhas foi usado nicosulfuron + bentazon.

A adubação foi feita na semeadura com $30 \mathrm{~kg}$ de $\mathrm{N}^{-1}{ }^{-1}$ (fonte: sulfato de amônio), $35,5 \mathrm{~kg}$ de $\mathrm{P}^{-1} \mathrm{C}^{-1}$ (fonte: superfosfato simples) e $41,5 \mathrm{~kg}$ de $\mathrm{K} \mathrm{ha}^{-1}$ (fonte: cloreto de potássio). Posteriormente foram feitas duas adubações em cobertura: $39 \mathrm{~kg}$ de $\mathrm{N}^{-1}$ (fonte: uréia) em 1 de outubro de 1998, e $60 \mathrm{~kg}$ de $\mathrm{N}^{-1}$ (fonte: uréia) em 27 de outubro de 1998.

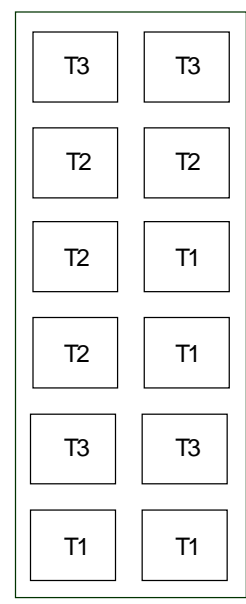

Lâmina 1

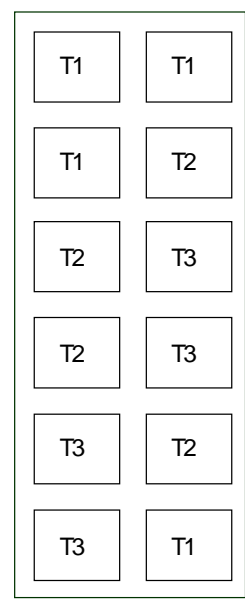

Lâmina 2
Figura 1 - Representação esquemática do conjunto de parcelas (Sendo: T1: D1 - densidade de 41176 planta ha ${ }^{-1}$; T2: D2 - densidade de 52941 planta ha-1; T3: D3 - densidade de 64706 planta ha ${ }^{-1}$; Lâmina 1 (L1): 40\% da regulagem do temporizador (lâmina média de 3,6 mm); Lâmina 2 (L2): $100 \%$ da regulagem do temporizador (lâmina média de $1,3 \mathrm{~mm})$. 
A fenologia da cultura de milho foi avaliada utilizando-se a escala proposta por Fancelli $(1986,1994)$ e Fancelli \& Dourado-Neto (1992), a qual subdivide o ciclo da cultura em diferentes estádios.

Foram calculados os graus-dia acumulados para cada estádio, utilizando-se as temperaturas basais mínima e máxima de $10^{\circ} \mathrm{C}(\mathrm{Tb})$ e $30^{\circ} \mathrm{C}(\mathrm{Tm})$, respectivamente. $\mathrm{O}$ desenvolvimento relativo ( $\mathrm{Dr}$ ) foi calculado no final do ciclo dividindo a soma calórica acumulada até a data correspondente a cada estádio fenológico pela soma calórica total (índice térmico, IT) no ponto de maturidade fisiológica.

O desenvolvimento relativo da cultura foi calculado por meio da seguinte equação:

$$
\operatorname{Dr}_{n}=\frac{\sum_{\mathrm{i}=1}^{\mathrm{n}}\left(\mathrm{T}_{\mathrm{i}}-\mathrm{T}_{\mathrm{b}}\right)}{\mathrm{IT}},(\mathrm{Tb} \leq \mathrm{Ti} \leq \mathrm{Tm})
$$

em que: $\operatorname{Dr}_{n}=$ estádio de desenvolvimento relativo da cultura até o n-ésimo dia após emergência $\left(0 \leq \operatorname{Dr}_{n} \leq 1\right)$; $\mathrm{T}_{\mathrm{i}}=$ temperatura média $\left({ }^{\circ} \mathrm{C}\right)$ do ar no i-ésimo dia após a emergência; $\mathrm{Tb}$ = temperatura basal mínima da cultura $\left(10^{\circ} \mathrm{C}\right)$; IT = índice térmico para atingir o ponto de maturidade fisiológica; $\mathrm{Tm}$ = temperatura basal máxima da cultura $\left(30^{\circ} \mathrm{C}\right)$.

A determinação da área foliar foi realizada da seguinte maneira: foram escolhidas aleatoriamente 6 plantas na área adjacente a cada grupo de 12 parcelas. Das folhas dessas plantas, foram retirados 30 círculos por planta $(n=30)$ com raio $(r, \mathrm{~cm})$ de $0,45 \mathrm{~cm}$ [exceto na primeira amostragem da lâmina 2 em que foram retirados $20(n=20)$ círculos por planta com raio de $0,75 \mathrm{~cm}]$, os quais foram secados e pesados; obtendo-se assim a correspondente massa de matéria seca $(\mathrm{mc}, \mathrm{g})$. Logo, com a área e a massa de matéria seca, foi obtida a área foliar específica $\left(\mathrm{AFe}, \mathrm{cm}^{2} \mathrm{~g}^{-1}\right)$ :

$$
A F e=\frac{n \cdot \pi \cdot r^{2}}{m c}
$$

A massa de matéria seca total das folhas das plantas amostradas foi obtida em cada uma das 12 parcelas de cada grupo. Assim, foi calculada a área foliar total (AFT, $\mathrm{cm}^{2}$ por planta) de cada planta a partir da área específica obtida em (2):

$$
A F T=M s f . A F e
$$

em que Msf se refere à massa de matéria seca das folhas por planta (g por planta).

Para o cálculo do índice de área foliar, utilizou-se a seguinte equação:

$$
I A F=\frac{A F T \cdot P}{10.000}
$$

em que $\mathrm{P}$ se refere à população de plantas (planta ha ${ }^{-1}$ ).
As amostragens foram feitas nos seguintes estádios fenológicos: i) 4 a 5 folhas, ii) 8 folhas e iii) 14 folhas. Na TABELA 1 são apresentadas as datas em que foram feitas as amostragens, o estádio fenológico correspondente e as lâminas aplicadas.

TABELA 1 - Datas de amostragens, estádios fenológicos correspondentes e lâminas aplicadas.

\begin{tabular}{llll}
\hline Amostragem & \multicolumn{1}{c}{ Data } & \multicolumn{1}{c}{$\begin{array}{c}\text { Estádio } \\
\text { fenológico }\end{array}$} & $\begin{array}{c}\text { Lâmina de } \\
\text { irrigação }\end{array}$ \\
\hline Primeira & 2 outubro & $4-5$ folhas & L2 (RT 100\%) \\
& 6 outubro & $4-5$ folhas & L1 (RT 40\%) \\
Segunda & 20 outubro & 8 folhas & L1 (RT 40\%) \\
& 21 outubro & 8 folhas & L2 (RT 100\%) \\
Terceira & 7 novembro & 14 folhas & L1 (RT 40\%) \\
& 8 novembro & 14 folhas & L2 (RT 100\%) \\
\hline
\end{tabular}

Em cada amostragem foram coletadas 2 plantas por parcela (exceto na primeira amostragem em que foram coletadas 3 plantas/parcela). Isto totaliza de 24 plantas por cada grupo de 12 parcelas, mais as 6 plantas que foram tiradas antes da passagem do pivô para a estimativa do conteúdo de água constitutiva. Também, nessas 6 plantas foram coletados os círculos de folhas para a determinação da área foliar.

No período entre amostragens, procedeu-se a présecagem das plantas, a separação das folhas do resto da plantas e a secagem em estufa, obtendo-se assim a massa seca de folhas e a massa seca das outras partes das plantas.

Foi proposta uma nova metodologia para avaliar diretamente a quantidade de água que fica retida nas folhas depois da irrigação (logo após a passagem do pivô). Para isso, foi necessário tirar as plantas inteiras depois da irrigação de maneira que fosse evitada a queda da água das folhas. As plantas foram coletadas em sacos plásticos e imediatamente pesadas. Por outro lado, foi necessário tirar plantas "controle" logo antes da irrigação para determinação do teor de água, assumindo-se que todas as plantas da lavoura, em um determinado momento do dia, têm o mesmo teor de água. Assim, conhecendo-se o teor de água e a massa de matéria seca da planta, pôdese determinar a quantidade de água constitucional.

As plantas após a pré-secagem em casa-devegetação, foram secadas em estufa a $70^{\circ} \mathrm{C}$ até peso constante.

O volume de água retido pela folhagem foi calculado pela diferença entre a massa da planta irrigada antes da secagem e a massa após a secagem, subtraindose o volume de água correspondente à massa de água constitucional. $O$ resultado foi dividido pela massa específica da água, a qual foi assumida igual $\mathrm{a} \mathrm{g} \mathrm{cm}^{-3}$. $\mathrm{O}$ procedimento matemático pode assim ser descrito: i) determinação do volume armazenado de água nas folhas:

$$
\mathrm{m}_{\mathrm{t}}=\mathrm{m}_{\mathrm{wc}}+\mathrm{m}_{\mathrm{s}}+\mathrm{m}_{\mathrm{we}}
$$




$$
\begin{aligned}
& \mathrm{m}_{\mathrm{we}}=\mathrm{m}_{\mathrm{t}}-\left(\mathrm{m}_{\mathrm{wc}}+\mathrm{m}_{\mathrm{s}}\right) \\
& \mathrm{U}=\frac{\mathrm{m}_{\mathrm{wc}}}{\left(\mathrm{m}_{\mathrm{s}}+\mathrm{m}_{\mathrm{wc}}\right)}
\end{aligned}
$$

Sendo assim:

$$
\begin{aligned}
& \mathrm{m}_{\mathrm{wc}}=\frac{\mathrm{U} \cdot \mathrm{m}_{\mathrm{s}}}{(1-\mathrm{U})} \\
& \mathrm{m}_{\mathrm{we}}=\mathrm{m}_{\mathrm{t}}-\frac{\mathrm{m}_{\mathrm{s}}}{(1-\mathrm{U})}
\end{aligned}
$$

em que $m_{t}$ se refere à massa total (planta irrigada antes da secagem), $m_{w c}$ à massa água constitucional, $m_{s}$ à massa matéria seca (massa planta irrigada após da secagem), $m_{\text {we }}$ à massa água externa, $U$ à umidade da planta vizinha a base de massa (controle) e $\mathrm{Vr}$ ao volume de água retido na folhagem da planta; ii) volume de água:

$$
\mathrm{Vr}=\frac{\mathrm{m}_{\mathrm{w}}}{\rho_{\mathrm{w}}}
$$

Sendo assim:

$$
\mathrm{Vr}=\frac{\mathrm{m}_{\mathrm{t}}}{\rho_{\mathrm{w}}}-\frac{\mathrm{m}_{\mathrm{s}}}{\rho_{\mathrm{w}}}\left[\frac{1}{(1-\mathrm{U})}\right]
$$

em que $m_{t}$ se refere à massa $(g)$ total (planta irrigada antes da secagem); $m_{s}$ à massa $(g)$ da matéria seca (massa planta irrigada após secagem); $U$ à umidade $\left(\mathrm{g} \mathrm{g}^{-1}\right) \mathrm{da}$ planta vizinha a base de massa (controle); $\mathrm{Vr}$ ao volume $\left(\mathrm{cm}^{3}\right)$ de água armazenado na folhagem da planta; $\rho_{\mathrm{w}}$ à massa específica da água, $\mathrm{g} \mathrm{cm}^{-3}$; iii) determinação da área foliar específica e área foliar total; iv) determinação da lâmina de água (h, mm por planta) que fica retida nas folhas da planta:

$$
\mathrm{h}=\frac{\mathrm{Vr}}{\mathrm{AFT}}
$$

em que $\mathrm{h}$ se refere à lâmina $(\mathrm{mm})$ de água retida; $\mathrm{V}_{\mathrm{r}}$ ao volume $\left(\mathrm{cm}^{3}\right)$ de água armazenado na folhagem da planta; AFT à área foliar $\left(\mathrm{cm}^{2}\right)$ da planta. Portanto, pode-se determinar a lâmina de água que fica retida nas folhas em função do volume de água retido e da área foliar total da planta; e v) determinação do volume de água retido na folhagem da cultura por hectare $\left(\mathrm{Vr}, \mathrm{L} \mathrm{ha}{ }^{-1}\right)$ :

$$
\mathrm{Vr}=\mathrm{h} \cdot \mathrm{IAF} \cdot 10^{4}
$$

em que $\mathrm{Vr}$ se refere ao volume $\left(\mathrm{L} \mathrm{ha}^{-1}\right)$ de água retido na parte aérea das plantas; $h$ à lâmina $(\mathrm{mm})$ de água retida; IAF ao índice de área foliar.
Para estimativa do índice de área foliar, foi proposto o seguinte modelo:

$$
I A F=a \cdot \mathrm{e}^{-\frac{-D r+b}{c}}+d \cdot \mathrm{e}^{\frac{-P+k}{f}}+g \cdot \mathrm{e}^{-\frac{-D r+b}{c}} \cdot \mathrm{e}^{-\frac{-P+k}{f}}
$$

em que Dr se refere ao desenvolvimento relativo da cultura, $\mathrm{P}$ à população de plantas (planta $\mathrm{m}^{-2}$ ) e $a, b, c, d$, $f, g$ e $k$ aos parâmetros empíricos determinados por meio de análise de regressão não linear minimizando a soma dos quadrados dos resíduos.

Para estimativa da lâmina retida ( $h, \mathrm{~mm})$, foi proposto o seguinte modelo:

$$
h=p\left(1-e^{-q \cdot D r}\right)
$$

em que $p$ e $q$ se referem aos parâmetros empíricos determinados por meio de análise de regressão não linear minimizando a soma dos quadrados dos resíduos.

Sendo assim, combinando as equações (13) (14) e (15), para estimativa do volume máximo retido $\left(\mathrm{Vr}, \mathrm{L} \mathrm{ha}{ }^{-1}\right)$ de água na folhagem da cultura de milho, obtém-se o seguinte modelo:

$V r=p\left(1-\mathrm{e}^{-q \cdot D r}\right) \cdot\left(a \cdot \mathrm{e}^{-\frac{-\mathrm{e}^{-}+b}{c}}+d \cdot \mathrm{e}^{\frac{-P+k}{f}}+g \cdot \mathrm{e}^{\frac{-D r+b}{c}} \cdot \mathrm{e}^{-\frac{\frac{-P+k}{f}}{f}}\right) 10^{4}(16)$

O volume máximo retido é estimado em função do índice de área foliar e do desenvolvimento relativo da cultura para fins de manejo e planejamento, respectivamente.

\section{RESULTADOS E DISCUSSÃO}

O conhecimento das fases de desenvolvimento de uma cultura é fundamental em estudos de distribuição de água aplicada devido à variabilidade espacial do índice de área foliar que modifica essa distribuição (Goodmann \& Smith, 1978). Os resultados das observações fenológicas referentes às épocas de amostragem são apresentados na TABELA 2.

A análise da variância (teste $F$ ) mostrou que os efeitos da população de plantas e da época de avaliação sobre o índice de área foliar (IAF) foram altamente significativos $(\alpha=0,01)$, o que justificou a utilização da análise de regressão. Esses atributos foram utilizados como variáveis independentes para a estimativa do índice de área foliar.

Pela análise de regressão, foi elaborado um modelo que explica a relação funcional do índice de área foliar com o a população de plantas e o desenvolvimento relativo da cultura de milho, em que o valor $\mathrm{F}$ e o coeficiente de correlação $(\alpha=0,01)$, permitiram verificar que o modelo proposto é utilizável (equação14, Figura 2, TABELA 3). 
TABELA 2 - Resultados das observações fenológicas.

\begin{tabular}{|c|c|c|c|}
\hline Estádio & Processo & $\begin{array}{l}\text { Dias após a } \\
\text { emergência }\end{array}$ & Data \\
\hline & Semeadura & & $27 / 8$ \\
\hline 0 & Emergência & 0 & $7 / 9$ \\
\hline 1 & $\begin{array}{l}4 \text { folhas to talmente } \\
\text { desdobradas }\end{array}$ & 20 & $27 / 9$ \\
\hline 2 & $\begin{array}{l}8 \text { folhas to talmente } \\
\text { desdobradas }\end{array}$ & 42 & $19 / 10$ \\
\hline 3 & $\begin{array}{l}12 \text { folhas to talmente } \\
\text { desdobradas }\end{array}$ & 55 & $1 / 11$ \\
\hline 4 & Emissão do pendão & 64 & $10 / 11$ \\
\hline 5 & Florescimento & 68 & $14 / 11$ \\
\hline 6 & Grãos leitosos & 77 & $23 / 11$ \\
\hline 7 & Grãos pastoso & 90 & $6 / 12$ \\
\hline 8 & Grãos duro & 109 & $25 / 12$ \\
\hline 9 & $\begin{array}{l}\text { Ponto de maturidade } \\
\text { fisiológica }\end{array}$ & 121 & $6 / 1$ \\
\hline
\end{tabular}

1 dias após emergência.

TABELA 3 - Modelo referente à estimativa do índice de área foliar (IAF) em função da população de plantas $\left(P\right.$, planta $\left.\mathrm{m}^{-2}\right)$ e do desenvolvimento relativo da cultura (Dr), com os respectivos valores do coeficiente de correlação (r), número de observações $(n)$, desvio padrão do erro (s), e valor F (Equação 14, Figura 2).

Parâmetros do modelo Parâmetros estatísticos

\begin{tabular}{cccccc}
\hline a & 3,122111 & K & 5,208344 & r & $0,996^{* *}$ \\
b & 0,260212 & F & 1,825842 & n & 18 \\
c & 0,073756 & G & 2,881399 & s & 0,2174 \\
d & 0,002427 & & & $F$ & $116,156^{* *}$ \\
\hline
\end{tabular}

** Significativo a $1 \%$.

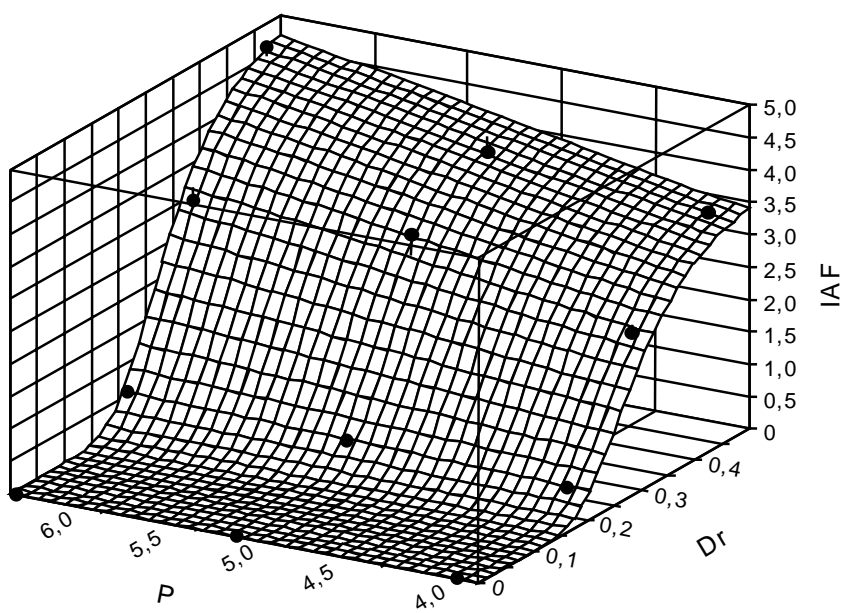

Figura 2 - Índice de área foliar (IAF) em função da população de plantas $\left(P\right.$, plantas $\left.\mathrm{m}^{-2}\right)$ e do desenvolvimento relativo da cultura (Dr) (Equação 14, TABELA 3).
A possibilidade de que possa ser estimado o IAF a partir desses dois parâmetros é uma ferramenta para 0 planejamento da cultura, pois conhecendo-se as características do material genético em relação ao seu desenvolvimento relativo pode-se estimar, para uma determinada população de plantas, o índice de área foliar que apresenta a cultura em um determinado momento, o que permitiria determinar o volume máximo de calda utilizável em quimigação foliar.

A análise da variância (teste F) para a variável lâmina retida mostrou que o efeito da população de plantas não foi significativo, e que o desenvolvimento relativo (representando a variável época de avaliação) foi altamente significativo $(\alpha=0,01)$.

Sendo assim, justifica-se pelo resultado da análise de variância, que a lâmina retida nas folhas é função do desenvolvimento relativo da cultura. $O$ valor $F$ e o coeficiente de correlação foram usados como critério para verificar que o modelo proposto é utilizável (equação 15, Figura 3, TABELA 4). Isso ocorre porque a medida em que a cultura apresenta maior índice de área foliar, maior é a sua capacidade de reter água. Isso não seria esperado se as folhas da cultura representassem uma área horizontal homogênea que interceptaria uma lâmina de água constante. Porém, devido à arquitetura de parte aérea, a medida em que as plantas de milho crescem e se desenvolvem, produzem um efeito "funil" armazenando água na inserção da folha no colmo na altura da bainha, tal como foi observado também por Stone et al. (1994) e Girardin (1992).

TABELA 4 - Modelo referente à estimativa da lâmina média retida (h, mm) em função do índice de área foliar (IAF) e do desenvolvimento relativo da cultura (Dr), com os respectivos valores do coeficiente de correlação $(r)$, número de observações (n), desvio padrão do erro (s, mm), e valor F (Equação 15, Figura 3).

\begin{tabular}{lcccccc}
\hline Modelo & $\mathrm{p}$ & $\mathrm{q}$ & $\mathrm{r}$ & $\mathrm{n}$ & $\mathrm{s}$ & $\mathrm{F}$ \\
\hline $\mathrm{h}=\mathrm{p}\left(1-\mathrm{e}^{-\mathrm{q} . D r}\right)$ & 0,18446 & 1,11144 & $0,732^{* *}$ & 18 & 0,01696 & $18,047^{* *}$ \\
\hline
\end{tabular}

** Significativo a $1 \%$.

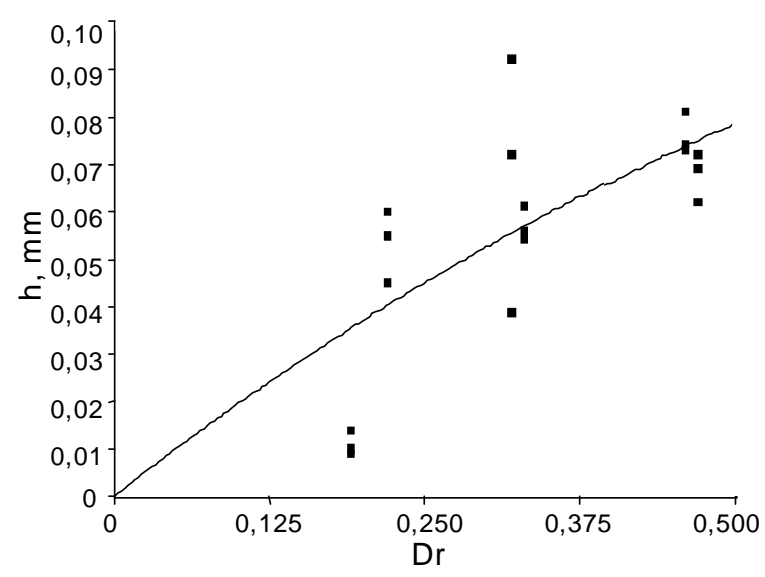

Figura 3 - Lâmina retida ( $h, \mathrm{~mm}$ ) em função do desenvolvimento relativo da cultura (Dr) (Equação 15, TABELA 4). 
Para efeito de planejamento, com o modelo proposto (equação 16), pode-se estimar o volume máximo de calda $\left(\mathrm{Vr}, \mathrm{L} \mathrm{ha}^{-1}\right)$ utilizável na aplicação foliar de um produto químico, para uma dada população de plantas com uma determinada idade (um determinado desenvolvimento relativo da cultura).

Ao nível de manejo da cultura, quando for necessária a aplicação de um produto químico cujo alvo for as folhas das plantas, o volume utilizável pode ser estimado em função do IAF. A possibilidade de se estimar o volume de calda máximo que pode ser retido na parte aérea das plantas é uma ferramenta para definir o equipamento adequado para se fazer uma aplicação mais eficiente do produto e verificar se a quimigação é recomendável.

Cabe salientar que o objetivo principal do trabalho é o do propor um modelo geral, para fins de planejamento, para determinar a ordem de grandeza do volume máximo de calda $\left(\mathrm{L} \mathrm{ha}^{-1}\right)$ armazenável na folhagem de milho, independentemente da forma de aplicação da calda. Poder-se-ia ter utilizado qualquer sistema de aplicação de água. Utilizou-se o sistema de irrigação do tipo pivô central por aplicar uma calda superior à máxima armazenável na folhagem, independentemente do índice de área foliar; e por ser um dos sistemas de irrigação onde a prática da quimigação é mais utilizada.

\section{CONCLUSÕES}

- O índice de área foliar pode ser estimado em função da população de plantas e do desenvolvimento relativo da cultura.

- A lâmina média retida pode ser estimada em função do desenvolvimento relativo da cultura.

- O modelo proposto permite determinar a ordem de grandeza do volume de calda máximo armazenável nas folhas da cultura de milho.

\section{REFERÊNCIAS BIBLIOGRÁFICAS}

CHRISTIANSEN, J.E. Irrigation by sprinkling. Berkeley: California Agricultural Experimental Station, 1942. (Bulletin 570)

FANCELLI, A.L. Plantas Alimentícias: guia para aula, estudos e discussão. Piracicaba: CALQ, 1986. 131p.
FANCELLI, A.L. Tecnologia da produção do milho para alta produtividade. Piracicaba: ESALQ/USP, Depto. de Agricultura, 1994. 223p.

FANCELLI, A.L.; DOURADO-NETO, D. Milho irrigado: considerações gerais para manejo. Piracicaba: ESALQ/USP, Depto. de Agricultura, 1992. 5p.

GIRARDIN, P. The "funnel effect" of a maize cannopy. In: EUROPEAN SOCIETY FOR AGRONOMY CONGRESS, 2., Warwick. Proceedings. Colmar: ESA, 1992. p.76-77.

GOODMANN, M.M.; SMITH, J.S.C. Botânica do milho. In: PATERNIANI, E. Melhoramento e produção do milho no Brasil. Piracicaba: Fundação Cargill, 1978. p.32-70.

LEON NEW, L.I. Introduction: why chemigate? In: LEON NEW, L.; KNUTSON, A.; BEAN, B.W., MORRISON, W.P.; PATRICK, C.D.; HICKEY, M.G.; KAUFMAN, H.W.; LEE, T.; AMOSSON, S.H.; FIPPS, G.; SWEETEN, J. Chemigation: workbook. Texas: Agriculture Extension Service, 1990. p. I-1.

LEOPOLDO, P.R. Aspectos hidrológicos de floresta amazónica densa na região de Manaus. Botucatu, 1981. 111p. Tese (Livre - Docência) - Universidade Estadual Paulista "Julho de Mesquita Filho".

LEOPOLDO, P.R.; SOUSA, A.P.; TUACEK FILHO, S. Intercepção da água de chuva em cultura de cana-de-açúcar. Brasil Açucareiro, v.98, p.9-16, 1981.

LIMA, W. de P. Interceptação da chuva em povoamentos de eucalipto e pinheiro. IPEF, v.13, p.75-90, 1976.

LINSLEY, R.K.; KOHLER, M.A.; PAULHUS, J.L.H. Applied Hydrology. New York: McGraw-Hill, 1949. 689p.

MIRANDA, R.A.C.; BUTLER, D.R. Interception of rainfall in a hedgerow apple orchard. Journal of Hydrology, v.87, p.245-253, 1986.

MUNDIM, P.M. Uniformidade de distribuição de água por aspersão convencional na presença da cultura do milho. Piracicaba, 1996. 82p. Dissertação (Mestrado) - Escola Superior de Agricultura "Luiz de Queiroz", Universidade de São Paulo.

RAO, A.S. Interception losses of rainfall from cashew trees. Journal of Hydrology, v.90, p.293-301, 1987.

STONE, K.C.; STANSELL, J.R.; YOUNG, J.R. Insecticide distribution through an irrigated corn canopy. Transations of the ASAE, v.37, p.135-138, 1994.

VIANA, P.A. Insetigação. In: COSTA, E.F.; VIEIRA, R.F.; VIANA, P.A. (Ed.) Quimigação: aplicação de produtos químicos e biológicos via irrigação. Brasília: EMBRAPA, SPI, 1994. p.249-268.

VIEIRA, R.F. Introdução à quimigação. In: COSTA, E.F.; VIEIRA, R.F.; VIANA, P.A. (Ed.) Quimigação: aplicação de produtos químicos e biológicos via irrigação. Brasília: EMBRAPA, SPI, 1994. p.13-40.

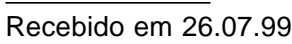

